\title{
VESSEL-LENGTH DISTRIBUTION IN BRANCHES, STEM AND ROOTS OF ACER RUBRUM L.
}

by

\author{
Martin H. Zimmermann and Daniel Potter \\ Harvard University, Cabot Foundation, Petersham, Massachusetts 01366, U.S.A.
}

\section{Summary}

Every part of the tree contains a range of vessel lengths, and always a much larger percentage of short than long vessels. Vessel diameter and longest vessel length increase from twigs to branches, down along the stem, to the long, rope-like roots. The percentage of vessels in the shortest length class decreases in the same direction. Although red maple is considered a diffuse-porous species, vessels in latewood are narrower and shorter than in the earlywood in any given part of the tree.

\section{Introduction}

Angiosperm vessels have remained rather elusive for many years. The difficulty is that they are microscopic structures that extend in length very far beyond the range of the microscopic view. Although the scanning electron microscope has a greater depth of field than the light microscope, it has given us only more information about vessel elements, but not about vessels. With the development of the method of cinematographic analysis (Zimmermann \& Tomlinson, 1965) it has become possible to see and demonstrate vessel ends clearly. We now know that vessels very rarely end in isolation. They usually taper out along neighbouring continuing vessels (e.g. Zimmermann, 1971). Such an arrangement makes sense if we consider that water must move repeatedly and efficiently from one vessel to the next on its way up into the leaves.

If vessels are cut open at both ends, it is possible to push gases (e.g. air) through them at modest pressures (such as $0.5 \mathrm{~atm}$.). This method has been used to measure maximum vessel length (Greenidge, 1952; Handley, 1936). However, the method does not give us any information about shorter vessels. Scholander (1958) described a method to determine 'average vessel length' by cutting successively longer pieces of stem off the upper end of a freshly cut, vertically held vine, and measuring the outflow of xylem sap at the lower end. This is an interesting approach, but it does not give us any information about vessels that are longer than the original piece of stem, a very impor- tant point in the case of vines where vessels may be rather long. The method also includes an error depending upon vessel diameter: capillarity holds back some of the xylem water. The paper of Skene and Balodis (1968) was a considerable step forward in that it introduced the concept of vessel-length distribution. In its initial form, the method was somewhat intractable, both from the experimental and mathematical point of view. However, in a recent paper by Zimmermann and Jeje (1981), two modified methods are described (latex paint perfusion and air-flow-rate measurements), and the mathematical treatment has been simplified in such a way that anyone can repeat the experiments and do the calculations with a hand or desk calculator.

The paper of Zimmermann and Jeje (1981) describes a survey of vessel-length distributions in various woody species of the northeastern United States with representatives of shrubs, trees and vines. The present paper describes vessel-length distribution in different parts of a single species, Acer rubrum L.

\section{Materials and Methods}

We originally intended to investigate a single tree only, by collecting and analysing first branches, then the stem, and finally the roots. This tree (Tree I) was a co-dominant that grew in a 40-year old stand where many of the specimens grew that had been used in our earlier measurements (Zimmermann \& Jeje, 1981).

Perfusion must be made with absolutely fresh material to avoid complications that might arise from both large-scale air blockage and tylosis formation. We could only handle about three infusions at any one time, because we had only three paint applicators, and these took about a week to be completed. The tree was therefore sampled in stages. We collected branches first by cutting them from the standing tree, thus leaving most of the tree intact. The trunk was finally cut, and paint infusions were made on trunk segments from three different heights. But as this tree was growing in rather rocky soil, it was difficult to obtain 


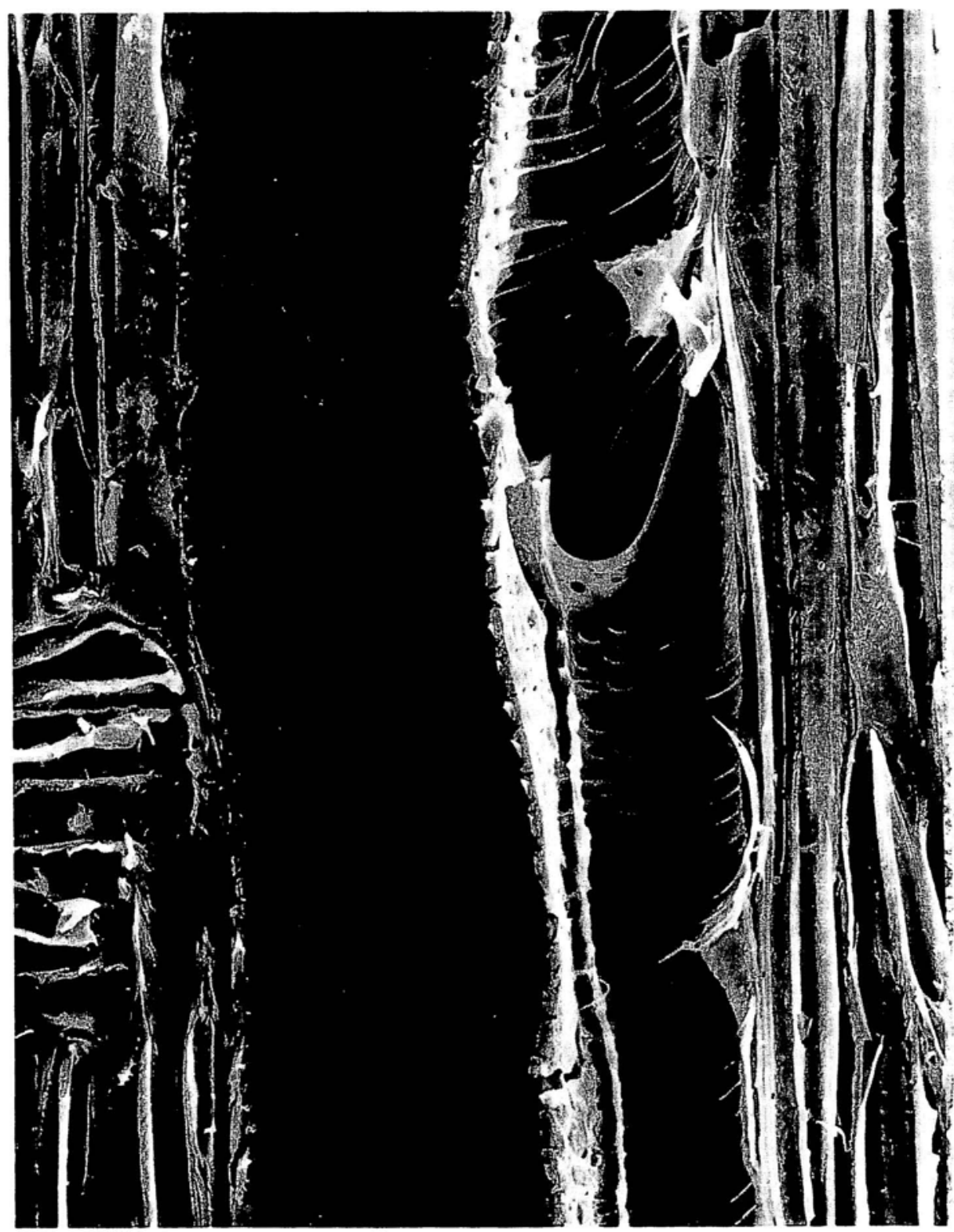

Fig. 1. Scanning electron micrograph of a longitudinal section of red maple wood infused with latex-paint particles. Of the two parallel-running vessels the one on the left has been infused, the one on the right not. The illustration shows that paint particles are too large to cross from one vessel to the next through the pit membranes, although they easily move across perforation plates (even if these are scalariform as in other species). 
roots. We therefore made most of our vessellength measurements with the roots of an individual maple that grew in a white pine stand. Pine roots grow rather deep and do not interfere much with the long, rope-like roots of red maple near the surface (Wilson, 1964). Additional measurements with branches and twigs were also made with other individual trees.

Freshly cut parts of trees (branches, trunks and roots) were brought immediately to the laboratory, cut shorter at both ends if feasible, to relax xylem tension, shaved smooth at one end with a razor blade or the microtome, and infused with a very dilute suspension of watersoluble latex paint (Zimmermann \& Jeje, 1981). Infusion was preceded by brief vacuum infiltration with distilled water in order to remove superficial air bubbles. Infusion took several days, until no more liquid was taken up. This concentrated the small paint particles by lateral loss of water from vessels (filtration) until the vessels that were cut open at the point of application were tightly packed with paint. Fig. 1 shows that paint particles are concentrated in the vessels to which the suspension has been applied until they are tightly packed, but they do not penetrate into adjacent, intact vessels. Larger stems were split longitudinally to remove the bulk of untreated wood. After completion of the paint infusion the axis was cut into 2 or $4 \mathrm{~cm}$ long segments. These were dried over night, the ends shaved with a microtome and the paint-filled vessels counted at the different distances from the point of application. The method permits separate analysis of individual growth rings. However, the results for individual growth rings were so similar that we only report total results here. In some cases we measured length distributions in the first and second half of a growth ring separately in order to obtain information about earlywood and latewood. The number of vessels counted at the point of application ranged from several hundred in roots to several thousand in stem and branches. For the conversion of vessel counts to length percentages the reader is referred to the paper by Zimmermann and Jeje (1981).

For the larger wood pieces we used the metal paint applicators described earlier (Zimmermann \& Jeje, 1981). For small-diameter branch and root samples however, paint applicators were made from glass. These have a shape very similar to the ones described earlier, but the piece of wood is attached inside the applicator, sealed against the glass by rubber tubing. We did not apply pressure to these, but completed the perfusion entirely by gravity feeding.
Hydraulic vessel diameters were calculated from measurements of largest and smallest inside diameters in a sample of 10 vessels. The calculation assumes that the transverse-sectional area is elliptical, and yields an inside diameter of a cylindrical capillary with equal flow resis-

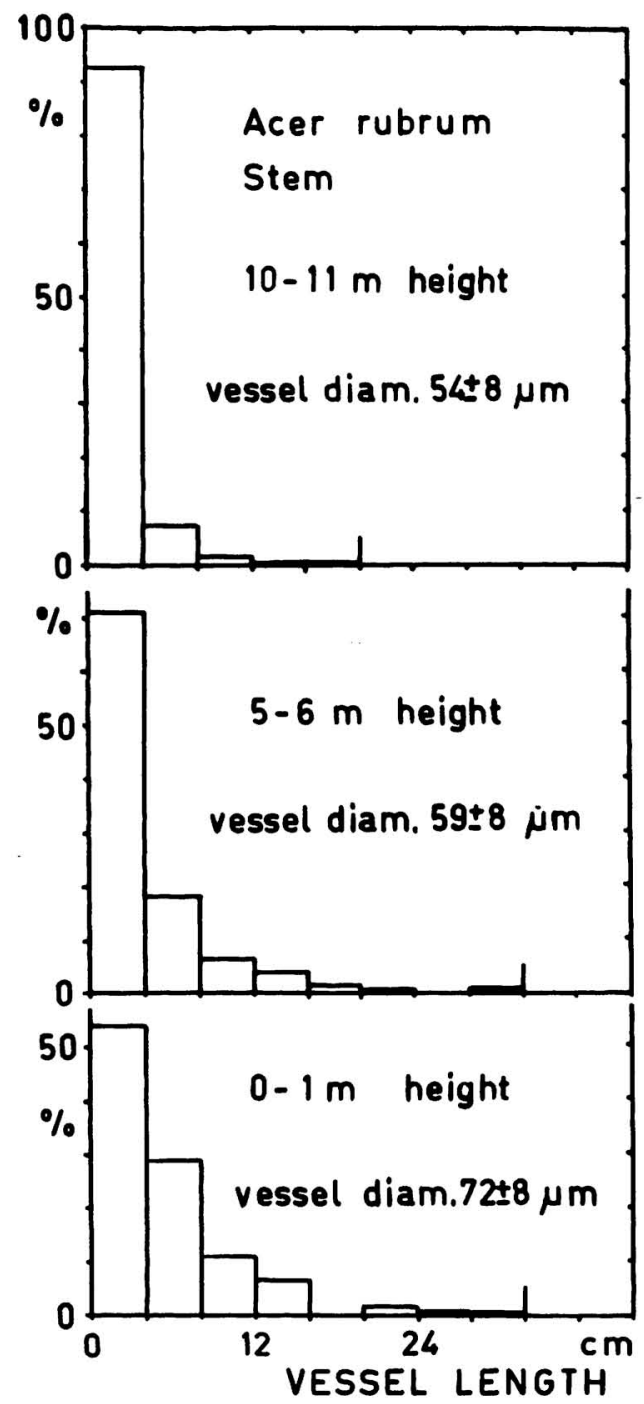

Fig. 2. Vessel-length distribution at three different heights in an individual trunk of Acer rubrum L. Not only vessel diameter, but also vessel length increases from top to bottom of the trunk. The small vertical lines at the right indicate longest lengths. 


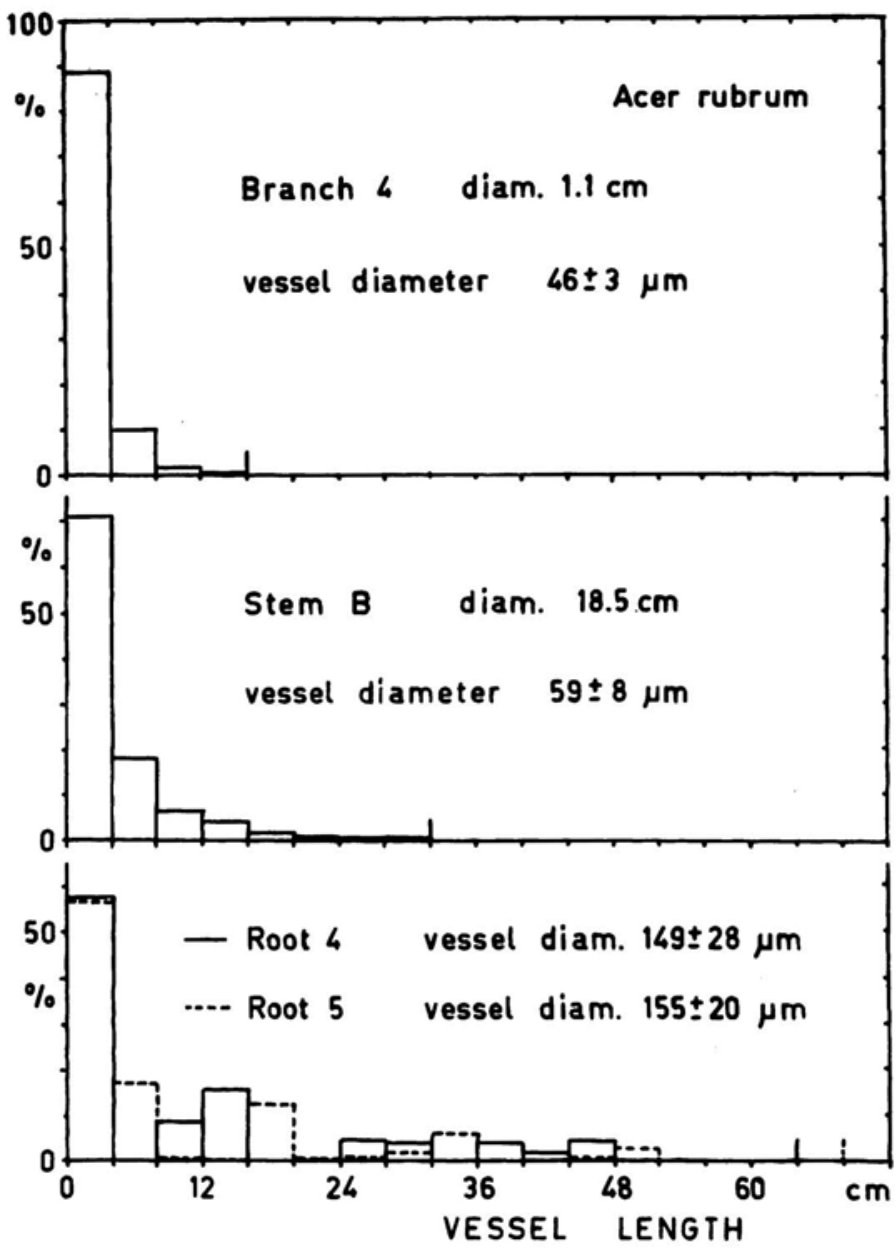

Fig. 3. Vessel-length distribution in a branch, trunk and two roots of Acer rubrum L. Measurements are given for two different roots. The small vertical lines at the right indicate longest lengths.

tance (Zimmermann \& Jeje, 1981, Appendix B).

Although we counted paint-filled vessels at two-centimeter distances in many cases, all results are given here for $4 \mathrm{~cm}$ intervals for better comparison. Root vessels are so long that $2 \mathrm{~cm}$ in tervals were unreasonably short.

Length distribution in different parts of the tree

Fig. 2 shows vessel-length distribution in the trunk of Tree I. Measurements were made on sections that were taken from the trunk at $0-1$, 5-6 and 10-11 meters height, at diameters of $21,18.5$ and $10 \mathrm{~cm}$ respectively. Hydraulic ves- sel diameters increased from $54 \mu \mathrm{m}$ at the ten meter level, to $72 \mu \mathrm{m}$ at the base of the trunk. Longest vessel length was $20 \mathrm{~cm}$ at the top, and $32 \mathrm{~cm}$ both at mid-height and at the base. The percentage of vessels in the shortest length class $(0-4 \mathrm{~cm})$, decreased from $92.3 \%$ at the top, to $70.7 \%$ at mid-height, to $53.3 \%$ at the base of the trunk.

Vessel-length determinations were made in five different branches. Some of the branches were taken from Tree I, others from other trees. In general, vessels were narrower and shorter in smaller branches. In fact, both vessel length and vessel diameter of above-ground axes cor- 
related rather well with the diameter of the axis from which they were taken. An example of vessel-length distribution and diameter in a c. $1.1 \mathrm{~cm}$ thick branch is given in Fig. 3 .

Certain roots are known to have large-diameter vessels (e.g. Riedl, 1937), especially the long, rope-like roots (Wilson, 1964). Five roots were excavated and perfused with paint. The results of two are given in Fig. 3 where they can be compared with those of stem and branch. Both of these roots had large-diameter and long vessels. Some of the roots, especially smaller ones with much taper, have smaller vessels. In the three specimens that are not shown in Fig. 3, maximum lengths were 34, 20 and $36 \mathrm{~cm}$ respectively, and hydraulic diameters were $112 \pm 13,91 \pm 15$, and $118 \pm 9 \mu \mathrm{m}$.

\section{Earlywood and latewood}

The correlation of vessel diameter and vessel length is most obvious when we compare the large earlywood vessels of our ring-porous trees either with the narrow latewood vessels of the same species, or with the narrow vessels of diffuse-porous wood. We have also found a significant difference in length distribution between the slightly wider earlywood and narrower latewood vessels in the wood of Prunus serotina Ehrh., a semi-ring-porous species (Zimmermann \& Jeje, 1981). Acer rubrum is considered diffuse-porous, i.e. 'wood in which the pores (vessels) are of fairly uniform or only gradually changing size and distribution throughout the growth ring' (Committee on Nomenclature, IAWA, 1964). When we measured hydraulic diameters in earlywood and latewood of Stem B (5-6 m height) in the 1977 growth ring, we found $57 \pm 9$ and $45 \pm 4 \mu \mathrm{m}$ respectively. Vessel lengths were also significantly different (Fig. 4).

\section{Discussion}

An important finding is the fact that in every part of the tree short vessels are very much more numerous than long vessels. Our calculations give percentages of vessels per transverse section (i.e. $x \%$ of the vessels seen in a single transverse section belong to a given length class). If we would express percentages per stem volume, the percentages of shorter vessels would be even greater.

Vessel diameter and length are correlated within a single species, specimen and even within a single growth ring. Fig. 5 shows this correlation for all our pooled results. It is somewhat surprising that longest lengths correlate better with diameter than the percentage in the shortest length class, because we found earlier that longest length is more variable than length distribution.
Finally, a word about the functional significance of vessel-length distribution may be in order. We know that wide and long vessels are more efficient conductors than narrow and short ones. At the same time, small conducting units are safer than large ones (Zimmermann, 1978a, 1982; Zimmermann \& Brown, 1971). This is particularly important in respect to vascular wilt diseases (Zimmermann \& McDonough, 1978). We also know that xylem pressures always decrease from bottom to top on account of gravity and flow resistance. There can be only one exception to this rule, namely a heavy rain when water may enter leaves and move basipetally in the xylem (Legge, 1980). If xylem pressures in the top of the tree are always lower than in the base, it is an advan-

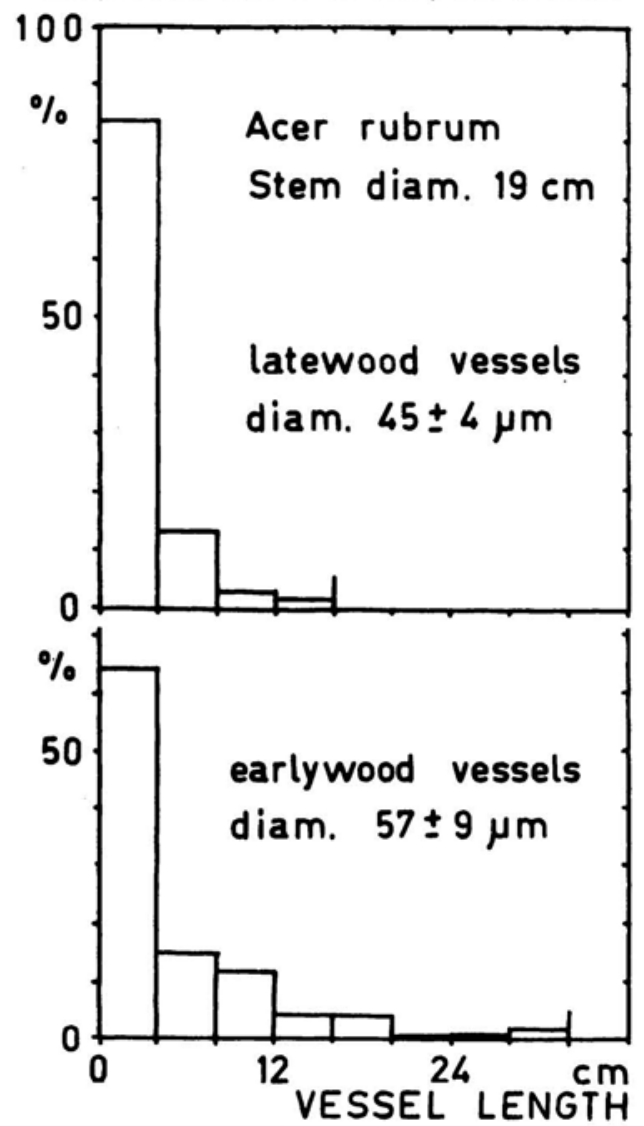

Fig. 4. Vessel-length distribution in earlywood and latewood of a stem compared. Although maple is considered a diffuse-porous species, earlywood and latewood vessels differ in diameter and length. The small vertical lines at the right indicate longest lengths. 


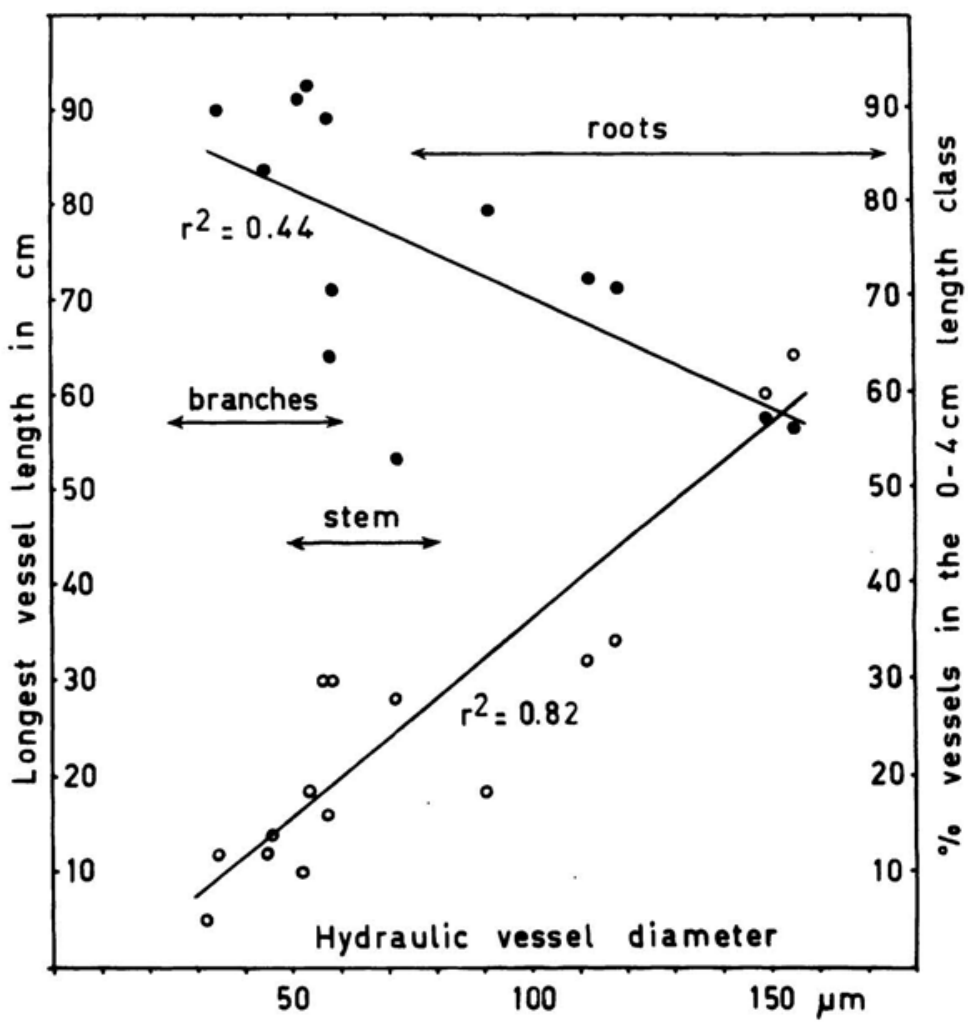

Fig. 5. Correlation of vessel diameters and lengths of pooled results.

tage to the tree to have the conducting compartments in the top smaller, i.e. safer. This is indeed the case. It has been known for some time that vessel diameters increase from the top to the bottom of a tree (e.g. Fegel, 1941; Zimmermann, 1978b, Fig. 6). The least stress is generally experienced by the xylem water of the roots. It is no surprise then that the largest vessels that have been found anywhere in the plant kingdom, have been found in roots (Jenik, 1978).

\section{Acknowledgements}

We wish to express our gratitude to Monica Mattmuller who assisted us in this work.

\section{References}

Committee on Nomenclature; IAWA. 1964. Multilingual glossary of terms used in wood anatomy. Konkordia, Winterthur.
Fegel, A.C. 1941. Comparative anatomy and varying physical properties of trunk, branch and root wood in certain northeastern trees. Bull. N.Y. State Coll. Forestry Syracuse Univ. Vol. 14, No. 2b. Tech. Publ. No. 55: 1-20.

Greenidge, K.N.H. 1952. An approach to the study of vessel length in hardwood species. Amer. J. Bot. 39: 570-574.

Handley, W.R.C. 1936. Some observations on the problem of vessel length determination in woody dicotyledons. New Phytol. 35: $456-471$.

Jeník J. 1978. Discussion. In:Tropiçal trees as living systems (eds. P.B. Tomlinson \& M.H. Zimmermann): 529. Cambridge University Press, Cambridge, U.K.

Legge, N.J. 1980. Aspects of transpiration in mountain ash Eucalyptus regnans F. Muell. $\mathrm{PhD}$. Thesis, LaTrobe University, Melbourne. 
Riedl, H. 1937. Bau und Leistungen des Wurzelholzes. (Structure and function of root wood). Jahrb. Wiss. Bot. 85: 1-75. (Xerox copy of English translation available from National Translation Center, 35 West 33rd St. Chicago, IL 60616, U.S.A.)

Scholander, P.F. 1958. The rise of sap in lianas. In: The physiology of forest trees (ed.K.V. Thimann): 3-17. Ronald Press, New York.

Skene, D.S. \& V. Balodis. 1968. A study of vessel length in Eucalyptus obliqua L'Hérit. J. Exptl. Bot. 19: 825-830.

Wilson, B.F. 1964. Structure and growth of woody roots of Acer rubrum L. Harvard Forest Paper No. 11.

Zimmermann,M.H. 1971. Dicotyledonous wood structure (made apparent by sequential sections). Description of Film E 1735. Inst. f. d. wiss. Film, Göttingen.

1978a. Structural requirements for optimal water conduction in tree stems. In: Tropical trees as living systems (eds. P.B. Tomlinson \& M.H. Zimmermann): 517532. Cambridge Univ. Press, Cambridge, U.K.
- 1978b. Hydraulic architecture of some diffuse-porous trees. Canad. J. Bot. 56: 2286-2295.

1982. Functional xylem anatomy of angiosperm trees. In: New perspectives in wood anatomy (ed. P. Baas): 59-70. Nijhoff/ Junk, The Hague.

_ \& C.L. Brown. 1971. Trees: structure and function. Springer-Verlag, New York, Heidelberg, Berlin.

_ \& A. Jeje. 1981. Vessel-length distribution in stems of some American woody plants. Canad. J. Bot. 59: 1882-1892.

- \& J. McDonough. 1978. Dysfunction in the flow of food. In: Plant disease. An advanced treatise (eds. J.G. Horsfall \& E.B. Cowling) Vol. 3: 117-140. Acad. Press, New York.

\& P.B. Tomlinson. 1965. Anatomy of the palm Rhapis excelsa. I. Mature vegetative axis. J. Arn. Arbor. 46: 160-180.

\section{REVIEW}

The Wood and Bark of Hardwoods growing on Southern Pine Sites - A Pictorial Atlas. Charles W. McMillin and Floyd G. Manwiller, 58 pp., numerous plates, 1980. Available free of charge from C.W. McMillin, Southern Forest Experiment Station, 2500 Shreveport Highway, Pineville, LA 71360 , U.S.A.

This handsome atlas gives $x$ 100-SEM photographs of properly tilted wood blocks showing the most salient features of the transverse, tangential and radial surfaces, as well as 1-colour photographs of radial and tangential views showing texture, grain and colour of the wood, transverse surfaces $(x 5)$ to show important lens characters, and $x$ 0.3-colour plates of the bark at standard stem diameter. The 23 species dealt with belong to 10 genera, Quercus being represented by 12 species. The photographic section is preceded by an introduction and an overview of hardwood structure. For the individual species valuable data are listed on the available resource on southern U.S.A. pine sites (expressed as million cubic $\mathrm{ft}$ and percent of total hardwood volumes), specific gravity of wood and bark, weight of green wood per cubic $\mathrm{ft}$, and moisture content of green wood and bark. With the modest aims implied in the title in mind, there can only be praise for this atlas. For the comparative wood anatomist and timber utiliser the atlas will doubtlessly induce curiosity and raise questions like: can the differences suggested by the photographs between the individual species of oak, elm and ash be used for diagnostic purposes? (I doubt this); can the differences in structure be related to properties?, etc. Perhaps these questions can be answered in a subsequent publication from the Southern Forest Experiment Station to which we are indebted for providing this atlas free of charge.

Pieter Baas 